\title{
Os sentidos da educação permanente em saúde para enfermeiras de um hospital infantil
}

RESUMO | Objetivo: Os sentidos da Educação Permanente em Saúde promovem significados e atribuições distintas. O objetivo geral do estudo foi analisar os sentidos da Educação Permanente em Saúde atribuídos pelas enfermeiras de um hospital infantil localizado na região sul do Brasil. Método: A abordagem do estudo foi qualitativa e, a coleta de dados, ocorreu mediante entrevistas individuais realizadas com nove participantes que integram um hospital infantil de referência. As categorias de análise foram compostas nos eixos: perfil das enfermeiras atuantes e Educação Permanente em Saúde pautada no Quadrilátero da Formação. Resultados: Os resultados indicam um perfil de enfermeira com média de idade de 40 anos, levando em consideração que apenas 33,3\% participam mensalmente das formações em Educação Permanente em Saúde com discussão de temas relacionados à gestão e à assistência. Conclusão: A pesquisa contribui para as discussões a respeito da sensibilização dos profissionais enfermeiros quanto aos sentidos do trabalho e a essência do cuidado à profissão.

Palavras-chaves: Educação Permanente em Saúde; Sentidos do Trabalho; Enfermagem.

\begin{abstract}
Objective: To analyze the meanings of work attributed to nurses at a children's hospital located in southern Brazil. Method: The study approach was qualitative and the data collection occurred through individual interviews with nine participants. The analysis categories were composed in the following axes: profile of the active nurses and Permanent Education in Health based on the Quadrilátero da Formação. Conclusion: The results indicate a nurse profile with an average age of 40 years and that only $33.3 \%$ participate monthly in Permanent Health Education with discussion of topics related to management and care. Considerations: The research contributes to the discussions regarding the awareness of nursing professionals regarding the meanings of work and the essence of care for the profession.
\end{abstract}

Keywords: Permanent Health Education; Senses of Work; Nursing.

RESUMEN | Objetivo: Analizar los significados del trabajo atribuidos a los enfermeros en un hospital infantil ubicado en el sur de Brasil. Método: El enfoque del estudio fue cualitativo y la recolección de datos se realizó a través de entrevistas individuales con nueve participantes. Las categorías de análisis se compusieron en los siguientes ejes: perfil de las enfermeras activas y Educación Permanente en Salud con base en el Quadrilátero da Formação. Conclusión: Los resultados indican un perfil de enfermero con una edad promedio de 40 años y que solo el 33,3\% participa mensualmente en Educación Permanente en Salud con discusión de temas relacionados con la gestión y el cuidado. Consideraciones: La investigación contribuye a las discusiones sobre la concienciación de los profesionales de enfermería sobre los significados del trabajo y la esencia del cuidado para la profesión.

Palabras claves: Educación en Salud Permanente; Sentidos del trabajo; Enfermería.

\section{Ana Claudia Delfini Capistrano de Oliveira}

Doutora em Sociologia Política, Docente, Itajaí (SC).

ORCID: 0000-0002-7154-9020

\section{Mayara Ana da Cunha Kersten}

Doutoranda em Educação, Docente, Itajaí (SC). ORCID: 0000-0002-6460-5207

\section{Rafaella Rebello}

Mestre em Educação, Enfermeira, Docente, Coordenadora do Eixo Saúde do Serviço Nacional de Aprendizagem Comercial (SENAC), Itajaí (SC).

ORCID: 0000-0002-8684-5981

\section{Sandy Aparecida Pereira}

Mestre em Educação, Docente, Porto Belo (SC). ORCID: 0000-0001-7504-6765

\section{Tania Regina Raitz}

Doutora em Educação, Docente, Itajaí (SC). ORCID: 0000-0002-4698-6077
Recebido em: 07/02/2021

Aprovado em: 26/02/2021

INTRODUÇão

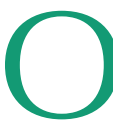
profissional de Enfermagem em sua prática profissional possui abrangente área de atuação que lhe possibilita desenvolver competências e habilidades requeridas em diversos setores de saúde. Durante a Graduação, essas atribuições são alicerçadas nos eixos da assistência, ensino, pesquisa e gerência ${ }^{(1)}$.

A composição destas quatro atribuições é baseada nas Diretrizes Curriculares Nacionais do Curso de Graduação em Enfermagem, publicadas na Resolução do Conselho Nacional de Educação $N^{0} 3$, de 7 de novembro de 2001 e previstas na Lei do Exercício Profissional № 7.498 de 25 de junho de $1986^{(2)}$.
As atribuições dadas à assistência de Enfermagem correspondem ao cuidado prestado às populações, considerando os determinantes socioculturais, econômicos e ecológicos do processo saúde-doença e seus princípios bioéticos; já a gerência subsidia a administração do processo de trabalho de Enfermagem. No eixo da pesquisa, o profissional de Enfermagem deve desenvolver, participar e aplicar pesquisas e produção de conhecimento que priorizem sua qualificação.

No que confere ao ensino, essas diretrizes trazem a Educação Permanente como um requisito necessário à formação do profissional Enfermeiro, considerando a promoção de oportunidades de ensino e responsabilidade com a educação e o treinamento dos profissionais nos serviços de saúde ${ }^{(3)}$. O papel central da Enfermagem na realização de ações edu- 
cativas, pois o Enfermeiro é o principal articulador dos diferentes setores do hospital$^{2}$. Entretanto, essa prática necessita de abordagem multiprofissional como forma de se tornar mais efetiva sob os diferentes olhares destes eixos.

No contexto educacional, temos a Educação Permanente, a qual se constitui como estratégia significativa para a viabilização das mudanças nas práticas de saúde, voltada para a melhoria da qualidade dos serviços ${ }^{(4)}$. É importante ressaltar que estudos trazem discussões a respeito da implantação de Núcleos de Educação Permanente no âmbito hospitalar, as quantificações de ações desenvolvidas pelos mesmos e suas limitações, a citar: pouco comprometimento dos profissionais e gestores, dificuldade relacionada à gestão de pessoas, gestão do tempo e falta de recursos físicos. Partindo destas reflexões, surge a motivação para a pesquisa: compreender os sentidos da Educação Permanente em Saúde para a Enfermagem e refletir sobre suas ações efetivas no âmbito hospitalar. O objetivo geral do estudo foi analisar os sentidos da Educação Permanente em Saúde atribuídos pelas enfermeiras de um hospital infantil na Região Sul do Brasil (1).

De acordo com o Decreto No 94.406, de 8 de junho de 1987, que regulamenta o exercício da Enfermagem, especifica-se claramente que ao Enfermeiro incumbe, como integrante da equipe de saúde, a "participação nos programas de treinamento e aprimoramento de pessoal de saúde, particularmente nos programas de educação continuada" (5).

No que confere na formação deste profissional, a Resolução do Conselho Nacional de Educação No 3, de 7 de novembro de 2001 prevê diversas competências e habilidades específicas, a citar: desenvolver formação técnico-científica que confira qualidade ao exercício profissional; planejar; implementar e participar dos programas de formação e qualificação contínua dos trabalhadores de Enfermagem e de saúde; reconhecer as relações de trabalho e sua influência na saúde e atuar como sujeito no processo de formação de recursos humanos, entre outras premissas ${ }^{(1)}$.

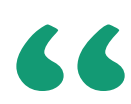

Parece correto afirmar que o Enfermeiro, na essência de sua profissão, tem na Educação Permanente um requisito para o exercício da prática profissional comprometida com as reais necessidades de saúde da população.

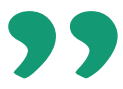

Parece correto afirmar que o Enfermeiro, na essência de sua profissão, tem na Educação Permanente um requisito para o exercício da prática profissional comprometida com as reais necessidades de saúde da população. Neste sentido, estudos anteriores trazem a relevância da participação dos profissionais de Enfermagem em ações de Educação Permanente em Saúde ${ }^{(6)}$. Vale ressaltar ainda a relevância do tema ressaltada pela Políti- ca Nacional de Educação Permanente em Saúde que foi instituída através da Portaria $N^{\circ} 198$ de 13 de fevereiro de 2004, preconizando a estratégia de formação e o desenvolvimento de trabalhadores para o Sistema Único de Saúde ${ }^{(7)}$.

Para direcionar a pesquisa, os estudos apontavam para responder a seguinte problemática: quais os sentidos da Educação Permanente em Saúde e do trabaIho atribuídos pelas enfermeiras de um hospital infantil? Diante da problematização, derivou o seguinte objetivo geral: analisar os sentidos da Educação Permanente em Saúde e do trabalho atribuídos pelas enfermeiras de um hospital infantil na Região Sul do Brasil.

\section{MÉTODO}

A abordagem do estudo foi qualitativa. A pesquisa foi realizada em 2019 num hospital infantil de referência na Região da Foz do Rio Itajaí Açú, na região Sul do Brasil. A instituição que tem grande parte de seu atendimento feito pelo Sistema Único de Saúde (SUS) e atualmente a gerência é feita por um grupo privado que administra e realiza a gestão hospitalar.

Os critérios de inclusão são todos os profissionais enfermeiros que trabalham na instituição. Fizeram parte do estudo os profissionais enfermeiros atuantes no hospital infantil nos setores: Unidade de atendimento A e B, centro cirúrgico, pronto socorro, unidade de terapia intensiva, comissão de controle de infecção hospitalar e gerência de Enfermagem nos turnos matutino, vespertino e noturno, totalizando 17 profissionais enfermeiros. Aceitaram participar da pesquisa 09 enfermeiras. O critério de exclusão foi profissionais que trabalham há menos de 1 mês na instituição. Ressalta-se que as enfermeiras (ENF) foram identificadas por números $(01,02,03)$.

O procedimento da coleta de dados se deu nas seguintes etapas: foi realizado um levantamento com a Gerência de Enfermagem para identificar e caracterizar, de acordo com os indicadores da pesqui- 
sa, os enfermeiros atuantes no hospital infantil. Com as informações obtidas, um convite impresso para participação voluntária da pesquisa foi entregue pessoalmente pela pesquisadora para cada enfermeiro do hospital. Para os que aceitaram participar, foi agendado juntamente com a Gerência de Enfermagem e com o participante uma entrevista individual numa sala privada disponível dentro do hospital. Foi verificado junto à Gerência e ao participante questões como o dimensionamento do quadro de Enfermagem e disponibilidade de melhor data e horário, de forma a não prejudicar o processo de trabalho do enfermeiro e não prejudicar a rotina do setor. Foram entregues aos participantes o Termo de Consentimento Livre e Esclarecido e fornecida todas as informações necessárias sobre a pesquisa, que já havia sido aprovada pelo Comitê de Ética em Pesquisa (CEP) por meio de número de parecer 3.097.649 e CAAE 00813318.5.0000.0120. Após assinatura do termo, foi feita a aplicação de um questionário com perguntas fechadas previamente elaboradas pelas pesquisadoras e entrevista com roteiro semiestruturado com perguntas abertas. Reforçamos que a data e horário para a realização da coleta de dados foram acordados com o participante e com a instituição (Gerência de Enfermagem), através de uma escala prévia de agendamento.

Utilizamos os referenciais de análise do conteúdo ${ }^{(8)}$, com a pré-análise, exploração do material e o tratamento de resultados com a codificação e inferência ${ }^{(9)}$. As categorias de análise foram compostas nos eixos: perfil das enfermeiras atuantes e a Educação Permanente em Saúde com seu Quadrilátero da Formação: ensino gestão - atenção/assistência e controle social. A coleta de dados integrou um período de 30 minutos até uma hora de entrevista realizada a cada participante.

\section{RESULTADOS}

Os resultados indicaram um perfil de enfermeira com média de idade de 40 anos, gênero feminino e orientação sexual heterossexual, casada, autodenominação étnica branca, residindo em Itajaí e com o cônjuge, com média de 2 filhos que só estudam. Em relação ao perfil profissional, temos profissionais com graduação recente, com tempo de formação de até 10 anos, 01 especialização concluída, turno de trabalho diurno, tempo de serviço no hospital de 3 meses e presença de 2 vínculos laborais, com renda mensal de 1 a 3 salários mínimos.

$\mathrm{Na}$ trajetória profissional, participavam mensalmente de Educação Permanente em Saúde com discussão de temas relacionados à gestão e à assistência, evidenciando uma preocupação e uma ligação do trabalho da Enfermagem focado apenas na área assistencial, da prática mecanizada de certos procedimentos, em detrimento às competências gerais na formação do Enfermeiro. A participação mensal e anual representaram 33,3\% e 22,2\%, respectivamente. Não houve constatação de participações em Educação Permanente em Saúde semanais.

Os eixos de gestão e assistência caracterizam uma demanda expressiva na área da Enfermagem. Ao realizar um levantamento de necessidades de ações educativas gerais com a equipe de Enfermagem de Pronto Socorro, estudos afirmam que $71,4 \%$ dos profissionais possuem interesse em temáticas de cunho técnico, 10,7\% em questões gerenciais e 14,3\% em questões de relações humanas ${ }^{(10)}$.

Quando questionadas se as ações de Educação Permanente que as mesmas participaram contribuíram para reflexões no seu ambiente de trabalho, a resposta foi unânime: 100\% consideraram que sim, contribuíram para reflexões. Entretanto, em relação à participação atual em ações de Educação Permanente em Saúde, apenas 3 enfermeiras (33,3\%) informaram que participam, enquanto 6 enfermeiras $(66,7)$ não participam atualmente. O que confirma a fragilidade da Educação Permanente em Saúde nas instituições hospitalares ${ }^{(11)}$.
A frequência na participação das ações educativas que encontramos no estudo diferem de outras realidades mencionadas em pesquisas na revisão de literatura. A frequência na participação das ações educativas realizadas com a equipe de Enfermagem foi diariamente $(35 \%)$ e de 1 a 3 vezes na semana $(15 \%){ }^{(12)}$. Em outro levantamento, 53,3\% dos sujeitos de pesquisa informaram que o hospital na qual trabalham desenvolvem poucas ações educativas de formação permanente e $100 \%$ acreditam que há a necessidade e o interesse de desenvolvimento de educação permanente com a equipe de Enfermagem ${ }^{(13)}$. O que nos remete à necessidade das instituições de saúde em desenvolverem estratégias de Educação Permanente em Saúde, na busca de valorização do ambiente didático pautado naquilo que produz sentido aos profissionais, com discussões a respeito da sensibilização dos enfermeiros sobre as práticas da Educação Permanente em Saúde nas instituições hospitalares, implementando ações crítico-reflexivas e considerando os sentidos do trabalho.

Quando questionamos sobre o que é Educação Permanente em Saúde, a pluralidade nas respostas das enfermeiras esteve presente:

Ah é os cursos, workshops, congressos que a gente possa fazer ao longo da profissão (ENF 01).

Aprendizado e conhecimento (ENF 04).

É uma educação importante (ENF 07).

(Pensante, houve um tempo até a resposta) Acho que é a capacitação frequentes das atividades e das técnicas executadas no dia a dia...não sei me expressar bem... é rever as técnicas, mais atuais (ENF 05).

(Pensante, houve um tempo até a resposta) É questão de rever as coisas, relembrar né (ENF 06). 
A dificuldade em responder o conceito foi evidenciado na fala de 3 enfermeiras, que se mostraram extremamente pensativas, com expressões faciais de estranhamento. A incerteza e insegurança nas respostas também esteve presente, com a sinalização da dificuldade em se expressar. As palavras "rever" e "relembrar" mencionadas nos traz a percepção da Educação Permanente em Saúde como replicadora daquilo que já existe ou que já se discutiu, sem possibilidade de brechas para novas reflexões, relacionadas ao trabalho. A Educação Permanente na trajetória profissional das enfermeiras entrevistadas foi desenvolvida como uma educação continuada, sendo que a pouca visibilidade das práticas se manifestou nas falas. Há perspectivas limitadas em relação a potencialidade da Educação Permanente em Saúde e dificuldades para diferenciar a Educação Permanente em Saúde e a educação continuada entre os enfermeiros ${ }^{(14)}$.

\section{DISCUSSÃO}

Num estudo sobre percepções dos enfermeiros acerca da educação permanente e continuada num hospital de ensino, os profissionais durante um grupo focal construíram a reflexão de que a educação permanente é desenvolvida com a formação da pessoa e relacionada às interações sociais enquanto que a educação continuada pode ser realizada por meio de cursos, sendo direcionada como uma educação formal. O conceito amplo da Educação Permanente em Saúde foi mencionado apenas na fala de uma enfermeira:

A Educação Permanente em Saúde é uma prática de ensino e aprendizado, uma produção do conhecimento, é do dia a dia, ela está inserida dentro do processo de trabalho. Ela vem da realidade, do conhecimento [...] da realidade vivenciada pelos profissionais, uma troca de saberes. Não quer dizer que aquilo que já sabemos ou aquilo que já fazemos é errado. Para haver um aprendizado tem que perguntar, tem que questionar, assim tem uma construção do que já se sabe e o que há por saber, o que há por vir (ENF 09).

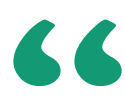

Há perspectivas limitadas em relação a potencialidade da Educação Permanente em Saúde e dificuldades para diferenciar a Educação Permanente em Saúde e a educação continuada entre os enfermeiros

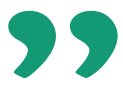

A fala retrata uma reflexão que vai além: ensino e aprendizado, processo de trabalho e cotidiano, construção e troca de saberes andando juntos. As referências mencionadas se constituem de palavras chave quando falamos de pressupostos de EPS, que são complementados pelo Qua- drilátero de Formação: ensino - gestão atenção/assistência e controle social, os quais interagindo entre si, viabilizam dignificar as características locais, as capacidades instaladas, o desenvolvimento de potencialidades, efetivando a aprendizagem significativa e o pensamento crítico, produzindo sentidos entre os profissionais de saúde ${ }^{(15)}$. Este quadrilátero embasou a construção dos eixos temáticos, os quais estão sendo descritos na pesquisa.

O papel da Educação Permanente em Saúde na Enfermagem perpassam os eixos do Quadrilátero de Formação e vem ao encontro das atribuições baseadas nas Diretrizes Curriculares Nacionais do Curso de Graduação em Enfermagem e previstas na Lei do Exercício Profissional $N^{\circ}$ 7.498 de 25 de junho de 1986 que são alicerçadas nos eixos da assistência, ensino, pesquisa e gerência. Para as enfermeiras, o papel da Educação Permanente em Saúde no trabalho e na trajetória profissional é definido como fundamental e importante:

Ah, eu acho fundamental, eu sou bastante interessada em workshop, congresso e pesquisa, tanto é que eu deixo sempre um espacinho ali que eu procuro sempre (ENF 01).

Pra mim eu acho que é importante, fundamental, para atualizar (ENF 02).

Importantíssimo, porque você consegue levar o conhecimento para a equipe, está vivenciando e mostrando para a equipe o que é certo, o que é errado e é motivação para eles, motivação para o trabalho (ENF 04).

Um dos pilares para que a gente tenha uma qualidade assistencial (ENF 08).

Eu acho que a educação permanente é fundamental para transformação do processo de trabaIho, tem que existir sempre né, senão não existe a qualidade no serviço prestado (ENF 09). 
A importância da Educação Permanente em Saúde envolve o fortalecimento da assistência à saúde, a segurança do paciente e a qualidade no serviço prestado, segundo as falas de ENF 05, 08 E 09. A cada questionamento e cada fala, a construção dos sentidos da educação permanente para as enfermeiras na trajetória profissional ganha cada vez mais forma: uma educação importante, porém de difícil conceitualização e prática distante daquela preconizada no trabalho. A insegurança pontuada no "eu acho" esteve presente em vários momentos e respostas durante a entrevista.

\section{CONCLUSÃO}

Os sentidos da Educação Permanente em Saúde foram analisados neste estudo através de olhares de 09 enfermeiras, com diferentes trajetórias profissionais e pessoais. Esta pesquisa contribui com discussões a respeito da sensibilização dos profissionais enfermeiros sobre as práticas da Educação
Permanente nas instituições hospitalares, implementando ações crítico-reflexivas na promoção de mudanças nas realidades de cada serviço.

A Educação Permanente em Saúde vale-se como uma oportunidade de aprendizado e crescimento profissional e pessoal, viabilizando as discussões sobre o trabalho. Entretanto, a discussão sobre Educação Permanente em Saúde causou estranheza e dúvidas para as participantes do estudo, evidenciando pouca clareza em relação aos objetivos e práticas destas ações educativas no âmbito hospitalar.

Apesar de descritas como Educação Permanente em Saúde, algumas ações relatadas pelas enfermeiras reproduziram apenas abordagens tradicionais, sem a aprendizagem significativa e pensamento crítico. Elas consideram uma educação importante, porém de difícil definição. $\mathrm{Na}$ trajetória profissional das enfermeiras, o Quadrilátero de Formação (ensino - gestão - atenção/assistência e controle social) foi enfatizado no eixo da assistência, ou seja, há uma preocupação e uma ligação do trabalho da Enfermagem focado apenas na área assistencial, da prática mecanizada de certos procedimentos, em detrimento às competências gerais na formação do Enfermeiro.

A Educação Permanente em Saúde nas trajetórias profissionais foram frágeis, evidenciando o foco de atualização de conhecimentos na prática da equipe de Enfermagem. Entretanto, as enfermeiras reconhecem a necessidade de ações educativas dentro da instituição hospitalar, identificando as potencialidades e fragilidades para o seu desenvolvimento. Conclusão foi remodelada

É necessário romper com a máxima de que a educação para enfermeiros é somente replicar ou relembrar técnicas contidas em procedimentos operacionais padrão. As demandas na educação para os trabalhadores de saúde devem surgir através da problematização do processo de trabalho, para que de fato, se consiga mudar as realidades e vincular uma qualidade assistencial para nossos pacientes e qualidade de vida para nossos trabalhadores de Enfermagem.

\section{Referências}

1. Rebello, R. Sentidos da Educação Permanente em Saúde e do Trabalho: um estudo sobre a trajetória profissional de enfermeiras de um hospital infantil da região sul do Brasil. 2019. Dissertação (Mestrado em Educação) - Universidade do Vale do Itajaí, Itajaí, 2019.

2. Brasil. Resolução CNE/CES n ${ }^{\circ} 3$, de 7 de novembro de 2001. Institui Diretrizes Curriculares Nacionais do Curso de Graduação em Enfermagem. Diário Oficial da União, Brasília, Seção 1, 2001.

3. Lavich, C. R. P. et al. Ações de educação permanente dos enfermeiros facilitadores de um núcleo de educação em enfermagem. Revista Gaúcha de Enfermagem, Porto Alegre, v. 38, n.1, 2017. Disponível em:http:// www.scielo.br/ scielo. php?script=sci_arttext\& pid=\$1983-14472017000100403\&lng=pt\&t|$\mathrm{ng}=$ pt. Acesso em: 20 abril 2018.

4. Lopes, A. G. et al. 0 desafio da Educação Permanente no trabalho da Enfermagem, Revista Multidisciplinar de Estudos Científicos em Saúde, v.1, n.1, 2016. Disponível em: http://revistaremecs.com.br/index.php/remecs/article/ view/. Acesso em: 20 abril 2018.

5. COREN SC. Conselho Regional de Enfermagem Santa Catarina. Cadernos de Enfermagem: Consolidação da Legislação e Ética Profissional. Florianópolis: 2013.

6. Sandri, J. V. de A.; Becker, G.; Gava, K.; Rebello, R. Caracterização das ações de Educação Permanente em Saúde no estado de Santa Catarina. Revista Brasileira de Tecnologias Sociais, Itajaí, v.1, n.2, 2014. Disponível em: https:/l siaiap32.univali.br/seer/index.php/rbts/article/view/7238. Acesso em: 27 abril 2018.

7. Brasil. Portaria GM/MS n 3.194 , de 20 de agosto de 2007. Dispõe sobre as diretrizes para a implementação da Política Nacional de Educação Permanente em Saúde e dá outras providências. Brasília, DF: Ministério da Saúde; 2007. 8. Bardin, L. Análise de conteúdo. São Paulo: Edições, 2016.

9. Franco, M. L. P. B. Análise de conteúdo. 3. ed. Brasília: Líber Livro, 2008. 10. Messias, M. Construção coletiva de programas educativos: potencialidade para consecução da educação permanente em saúde. 2015. Tese (Doutorado em Ciências) - Escola de Enfermagem, Universidade de São Paulo, 2015.

11. Formenton, Y. F. Educação permanente em saúde: representações sociais de enfermeiros da saúde da família. 2013. Dissertação (Mestrado em Enfermagem) - Universidade Federal de São Carlos, São Carlos, 2013.

12. Silva, U. G. Educação permanente em saúde: práticas humanizadas no centro obstétrico de um hospital universitário. 2013.Dissertação (Mestrado em Enfermagem) - Universidade do Vale do Rio do Sinos, Porto Alegre, 2015. 13. Araújo, K. Q. M. A. Núcleo De Educação Permanente Como Ferramenta De Gestão Organizacional No Hospital Universitário Ana Bezerra: Um Plano De Projeto Técnico Aplicado. 2015. Dissertação (Mestrado em Gestão de Organizações Aprendentes) - Programa de Pós Graduação Profissional em Gestão de Organizações Aprendentes, Universidade Federal da Paraíba, João Pessoa, 2015.

14. Valente, D. da S. Educação permanente em unidade críticas de um hospital de ensino: elaboração de material de apoio. 2015. Dissertação (Mestrado em Enfermagem) - Universidade Estadual Paulista Júlio de Mesquita Filho, Botucatu, 2015.

15. Ceccim, R. B.; Fuerwerker, L. 0 Quadrilátero da Formação para a Área da Saúde. Revista Saúde Coletiva, Rio de Janeiro, v.14, n.1, 2004. 